Tetrahedron Letters

journal homepage: www.elsevier.com

\title{
Potassium Iodide Promoted Thiolation of Pyrazolones and Benzofurans Using Aryl Sulfonyl Chlorides as Sulfenylation Reagents
}

\author{
Xia Zhao ${ }^{\mathrm{a},} *$, Xiaoyu Lu ${ }^{\mathrm{a}}$, Aoqi Wei ${ }^{\mathrm{a}}$, Xiaoliang Jia ${ }^{\mathrm{b}}$, Jun Chen ${ }^{\mathrm{c}}$ and Kui Lu ${ }^{\mathrm{b}}{ }_{*}$ \\ ${ }^{a}$ College of Chemistry, Tianjin Key Laboratory of Structure and Performance for Functional Molecules, Key laboratory of Inorganic-organic Hybrid Functional \\ Material Chemistry, Ministry of Education, Tianjin Normal University, Tianjin 300387, China \\ ${ }^{b}$ College of Biotechnology, Tianjin University of Science \& Technology, Tianjin 300457, China \\ ${ }^{c}$ Beijing Institute of Microchemistry, Beijing 100091, China
}

\section{ARTICLE INFO}

Article history:

Received

Received in revised form

Accepted

Available online

\section{Keywords:}

Thiolation

Pyrazolone

Benzofuran

Sulfonyl Chloride

Potassium Iodide

\section{ABSTRACT}

An efficient, transition-metal-free method to synthesize pyrazolone thioethers as well as 2-aryl and 3-aryl benzofuran thioethers by employing aryl sulfonyl chlorides as sulfenylation reagents in the presence of triphenylphosphine was developed. Potassium iodide was found to facilitate the transformation for the first time by generating more reactive sulfenyl iodide in situ from sulfenyl chloride.

\section{Introduction}

Carbon-Sulfur $(\mathrm{C}-\mathrm{S})$ bond-forming reactions play a pivotal role in the synthesis of organo-sulfur compounds of pharmaceutical and material interest. ${ }^{1}$ Therefore, exploration of new methods for $\mathrm{C}-\mathrm{S}$ bond generation has attracted much attention in recent years. ${ }^{2}$ Although transition-metal-catalyzed C$\mathrm{S}$ bond formation reactions could avoid harsh condition as well as toxic polar solvents with high boiling temperatures, expensive and often air-sensitive catalysts as well as foul-smelling, unstable and volatile sulfur sources limitted their further application ${ }^{3}$ Recently, sulfonyl hydrazides have emerged as a novel and environmental-friendly sulfenylation reagents because they are generally stable, readily accessible, and odor-free. ${ }^{4}$ To the best of our knowledge, the synthetic precursor sulfonyl chlorides have rarely been reported to be sulfenylation reagents, although they are used as sulfonylating reagents as well as arylation reagents in $\mathrm{C}-\mathrm{C}$ cross coupling reactions. In 2011, You and co-workers reported an efficient thiolation of indolizines, indoles and electron-rich benzenes using aryl sulfonyl chlorides as sulfenylation reagents in combination with $\mathrm{PPh}_{3}$ as reductant. ${ }^{5}$ In 2012, Zheng and coworkers reported $\mathrm{Ru}(\mathrm{bpy})_{3} \mathrm{Cl}_{2}$ catalyzed visible light-induced 3 -sulfenylation of $\mathrm{N}$-methylindoles with arylsulfonyl chlorides (Scheme 1). ${ }^{6}$ As a part of ongoing our interests in exploring new sulfenylation reagents, we have developed an iodine catalyzed thiolation of pyrazolones, ${ }^{7}$ benzofurans $^{8}$ and electron-rich aromatics ${ }^{9}$ with sulfonyl hydrazides as the sulfur source. Herein, we would like to report a novel potassium iodide facilitated thiolation reaction of pyrazolones and benzofurans with aryl sulfonyl chlorides as sulfenylation reagents.

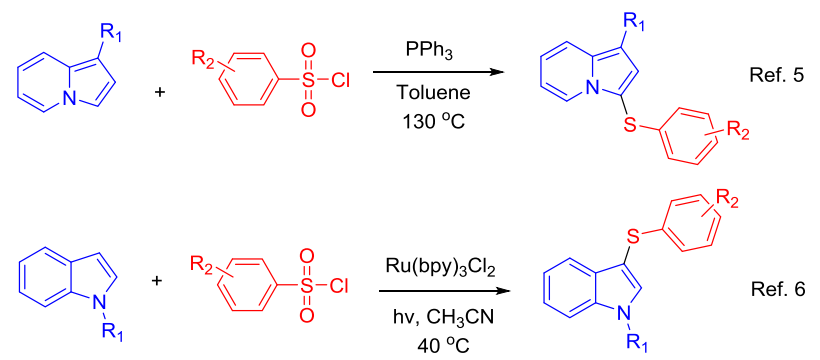

Scheme 1 Thiolation of indolizines and $N$-methylindoles using sulfonyl chlorides as sulfenylation reagents

\section{Results and discussion}

To probe the thiolation of heterocyclic compounds like pyrazolones and benzofurans, we employed the reaction of 5methyl-2-phenyl-2,4-dihydro-3H-pyrazol-3-one $\mathbf{1 a}$ and 4 methylbenzenesulfonyl chloride $\mathbf{2 a}$ as the model reaction and $\mathrm{PPh}_{3}$ as reductant. The reaction in toluene at $70{ }^{\circ} \mathrm{C}$ gave the desired thiolation product 3aa in $49 \%$ yield (Table 1, Entry 1). To improve the yield, a series of solvents such as 1,2-

* Xia Zhao. Tel.: +86 22 23766531; fax: +86 2223766531; e-mail: hxxyzhx@ mail.tjnu.edu.cn

* Kui Lu. Tel.: +86 22 60912562; fax: +86 22 60602298; e-mail: lukui@ tust.edu.cn 
dichloroethane (DCE), 1,4-dioxane and $N, N$ dimethylformamide (DMF) were investigated (Table 1, Entry 24) and 1,4-dioxane gave the best yield. Next, temperature and additive effects were evaluated from $80{ }^{\circ} \mathrm{C}$ to $100{ }^{\circ} \mathrm{C}$. When the reaction was carried out at $80^{\circ} \mathrm{C}$ and $90{ }^{\circ} \mathrm{C}$, the yield increased to $65 \%$ (Table 1, Entries 5 and 6). However, further increasing the reaction temperature to $100{ }^{\circ} \mathrm{C}$ led to a diminished yield (Table 1 , Entry 7). Notably, when 0.2 equiv. potassium iodide (KI) was added, the yield increased dramatically to $90 \%$ yield (Table 1 , Entry 8), while the classical iodide anion source tetra- $n$ butylammonium iodide $\left(n \mathrm{Bu}_{4} \mathrm{NI}\right)$ decreased the yield (Table 1 , Entry 9). Finally, equivalents of $\mathbf{2 a}, \mathrm{PPh}_{3}$ and $\mathrm{KI}$ as well as the reaction concentration were investigated (Table 1, Entries 10-15). For sulfonyl chloride, 1.2 equiv. of $\mathbf{2 a}$ gave the highest yield, and decreasing the amount of 2a led to a diminished yield (Table 1, Entry 10). For reductant, 2.0 equiv. of $\mathrm{PPh}_{3}$ were sufficient to obtain a yield of $90 \%$, and further increasing the amount of the $\mathrm{PPh}_{3}$ did not affect the yield (Table 1, Entry 11). For additive, 0.2 equiv. of KI gave a yield of $90 \%$ as shown above. Decreasing the KI amount to 0.15 equivalent led to a decreased yield (Table 1, Entry 12), while further increasing the amount did not affect the yield (Table 1, Entry 13). It was noteworthy that increasing or decreasing the concentration both diminished the yield (Table 1, Entries 14 and 15). Therefore, the reaction conditions were optimized to be as follows: $\mathbf{1 a}(0.5 \mathrm{mmol}), \mathbf{2 a}(0.6 \mathrm{mmol}), \mathrm{PPh}_{3}$ $(1.0 \mathrm{mmol}), \mathrm{KI}(0.1 \mathrm{mmol})$ and 1,4 -dioxane $(1 \mathrm{~mL})$, at $80^{\circ} \mathrm{C}$.

Table 1 Optimization of the thiolation of $\mathbf{1 a}$ with $\mathbf{2 a}$ in the presence of $\mathrm{PPh}_{3}{ }^{\text {a }}$

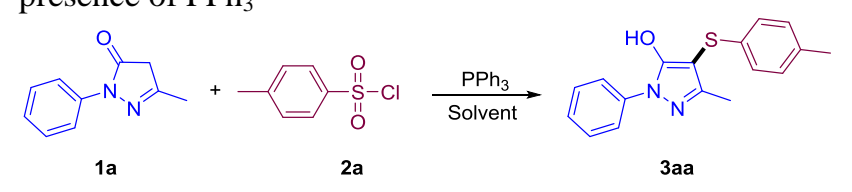

\begin{tabular}{|c|c|c|c|c|c|}
\hline Entry & KI (equiv) & $\mathrm{T}\left({ }^{\circ} \mathrm{C}\right)$ & Solvent & Volume (mL) & Yield (\%) \\
\hline 1 & - & 70 & Toluene & 1.0 & 49 \\
\hline 2 & - & 70 & DCE & 1.0 & 32 \\
\hline 3 & - & 70 & DMF & 1.0 & 48 \\
\hline 4 & - & 70 & 1,4-dioxane & 1.0 & 55 \\
\hline 5 & - & 80 & 1,4-dioxane & 1.0 & 65 \\
\hline 6 & - & 90 & 1,4-dioxane & 1.0 & 65 \\
\hline 7 & - & 100 & 1,4-dioxane & 1.0 & 37 \\
\hline 8 & 0.2 & 80 & 1,4-dioxane & 1.0 & 90 \\
\hline 9 & $0.2^{\mathrm{b}}$ & 80 & 1,4-dioxane & 1.0 & 56 \\
\hline 10 & 0.2 & 80 & 1,4-dioxane & 1.0 & $79^{c}$ \\
\hline 11 & 0.2 & 80 & 1,4-dioxane & 1.0 & $90^{\mathrm{d}}$ \\
\hline 12 & 0.15 & 80 & 1,4-dioxane & 1.0 & 78 \\
\hline 13 & 0.25 & 80 & 1,4-dioxane & 1.0 & 90 \\
\hline 14 & 0.2 & 80 & 1,4-dioxane & 1.5 & 79 \\
\hline 15 & 0.2 & 80 & 1,4-dioxane & 0.5 & 71 \\
\hline
\end{tabular}

The substrate scope of the sulfenylation reaction was investigated under the optimized conditions. As shown in Table 2, a series of substituted pyrazolones could be coupled with various substituted aryl sulfonyl chlorides to afford the corresponding pyrazolone thioethers in moderate to excellent yields. ${ }^{10}$ For pyrazolones, both aryl groups (1a-1d) and alkyl groups (1e-1h) on 1-position were well tolerated. Moreover, pyrazolones bearing phenyl, benzyl and methyl groups on 3position could be readily converted to the desired products in good yields.

For aromatic sulfonyl chloride, both electron-donating and electron-withdrawing groups, as well as ortho-, meta-, and parasubstitutions (2a-2j) were tolerated in the reaction. Notably, for steric effect, phenyl sulfonyl chloride with an ortho-methyl group provided pyrazolone thioether in a relatively low yield compared with the corresponding para-methyl group (3aa versus 3ad, 3ea versus 3ed).
Table 2 Thiolation of pyrazolones with aryl sulfonyl chloride in the presence of $\mathrm{PPh}_{3}{ }^{\mathrm{a}}$

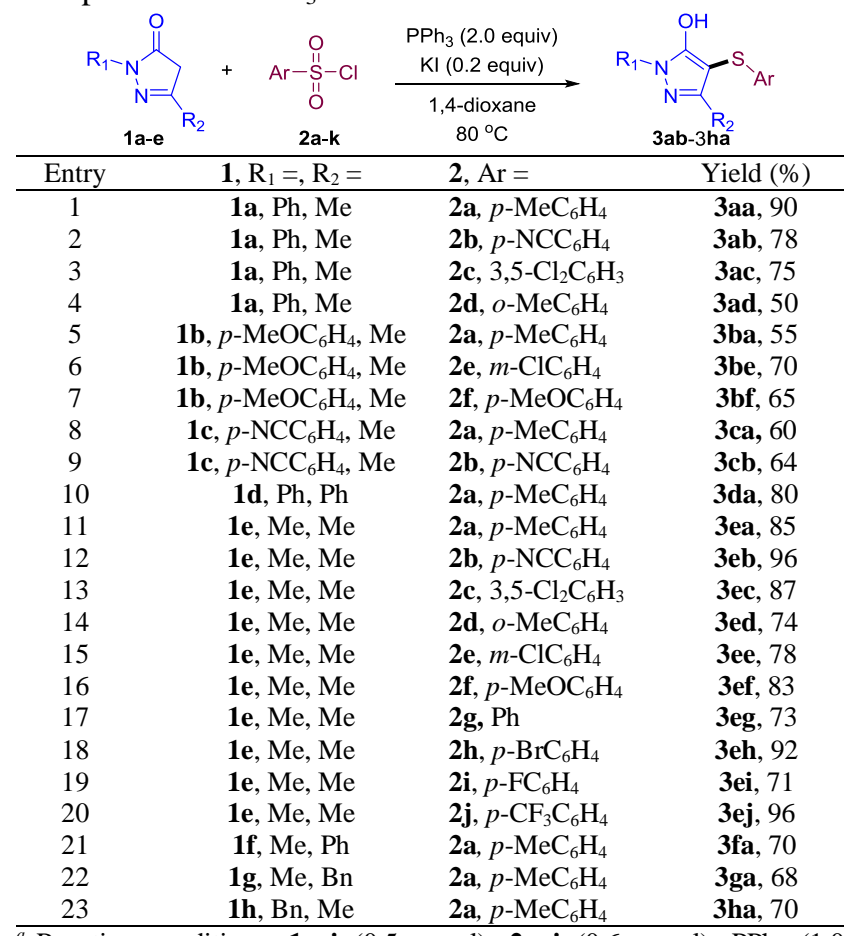

${ }^{a}$ Reaction conditions: 1a-i $(0.5 \mathrm{mmol}), \mathbf{2 a}-\mathbf{j}(0.6 \mathrm{mmol}), \mathrm{PPh}_{3}(1.0$ $\mathrm{mmol}), \mathrm{KI}(0.1 \mathrm{mmol}), 1,4$-dioxane $(1 \mathrm{~mL}), 80^{\circ} \mathrm{C}, 12 \mathrm{~h}$.

The reaction condition was then explored for the thiolation of benzofuran derivatives. Considering the relatively less nucleophilicity of benzofuran versus pyrazolone, the reaction of 2-(4-methoxyphenyl)benzofuran (4a) with $\mathbf{2 a}$ was carried out in the presence of $\mathrm{PPh}_{3}$ and $\mathrm{KI}$ at $100{ }^{\circ} \mathrm{C}$ in 1,4-dioxane, and the desired thiolation product 5aa was obtained in 58\% yield (Table 3 , Entry 1). To improve the yield, varied solvents such as DCE, $\mathrm{DMF}$, toluene, ethanol (EtOH) and isopropanol $(i-\mathrm{PrOH})$ were tested (Table 3, Entry 2-6), and EtOH gave the highest yield of $80 \%$. Reaction temperatures and KI equivalents were evaluated as well. Increasing the reaction temperature to $110{ }^{\circ} \mathrm{C}$ did not affect much on the yield (Table 3, Entry 7 ), while decreasing the reaction temperature to $90{ }^{\circ} \mathrm{C}$ led to an increase of the yield to $90 \%$ yield (Table 3, Entry 8). However, further decreasing the reaction temperature to $80{ }^{\circ} \mathrm{C}$ diminished the yield (Table 3 , Entry 9). Decreasing KI loading to 0.15 equiv. or 0.1 equiv. led to a decrease of the yield (Table 3, Entries 10 and 11). Finally, concentration screening demonstrated that decreasing or increasing reactant concentrations led to a decrease of the yield (Table 3, Entries 12 and 13). Thus, the optimized reaction conditions for thiolation of $\mathbf{4 a}$ were as follows: $\mathbf{4 a}(0.5 \mathrm{mmol}), \mathbf{2 a}$ (0.6 mmol), $\mathrm{PPh}_{3}(1.0 \mathrm{mmol}), \mathrm{KI}(0.1 \mathrm{mmol})$ and $\mathrm{EtOH}(1 \mathrm{~mL})$, at $90{ }^{\circ} \mathrm{C}$.

Table 3 Optimization of the thiolation of $\mathbf{4 a}$ with $\mathbf{2 a}$ in the presence of $\mathrm{PPh}_{3}{ }^{a}$

\begin{tabular}{|c|c|c|c|c|c|}
\hline & $4 a$ & & $2 a$ & \multicolumn{2}{|c|}{5 aa } \\
\hline Entry & KI (equiv) & $\mathrm{T}\left({ }^{\circ} \mathrm{C}\right)$ & Solvent & Volume (mL) & Yield (\%) \\
\hline 1 & 0.2 & 100 & 1,4-dioxane & 1.0 & 58 \\
\hline 2 & 0.2 & 100 & DCE & 1.0 & 0 \\
\hline 3 & 0.2 & 100 & DMF & 1.0 & trace \\
\hline 4 & 0.2 & 100 & Toluene & 1.0 & 0 \\
\hline 5 & 0.2 & 100 & $\mathrm{EtOH}$ & 1.0 & 80 \\
\hline 6 & 0.2 & 100 & $i$-PrOH & 1.0 & 69 \\
\hline 7 & 0.2 & 110 & EtOH & 1.0 & 79 \\
\hline 8 & 0.2 & 90 & $\mathrm{EtOH}$ & 1.0 & 90 \\
\hline 9 & 0.2 & 80 & $\mathrm{EtOH}$ & 1.0 & 80 \\
\hline 10 & 0.15 & 80 & $\mathrm{EtOH}$ & 1.0 & 87 \\
\hline 11 & 0.1 & 80 & EtOH & 1.0 & 86 \\
\hline
\end{tabular}




\begin{tabular}{cccccc}
12 & 0.2 & 80 & EtOH & 0.5 & 80 \\
13 & 0.1 & 80 & EtOH & 1.5 & 80 \\
\hline \multicolumn{5}{r}{ Reaction conditions: } \\
\multicolumn{7}{r}{$\mathbf{4 a}(0.5 \mathrm{mmol}), \mathbf{2 a}(0.6 \mathrm{mmol}), \mathrm{PPh}_{3}(1.0 \mathrm{mmol})$}
\end{tabular}

Under the optimized reaction conditions for thiolation of benzofurans $\mathbf{4 a}$, a series of 2 -substituted benzo[b]furans was coupled with varied of aryl sulfonyl chlorides in the presence of $\mathrm{PPh}_{3}$ (Table 4). Aryl sulfonyl chlorides with electron-donating or electron-withdrawing substituents at ortho-, meta- or paraposition were reacted with $\mathbf{4 a}$, and the reactions gave the desired products in good to excellent yields. However, the reaction of 2phenylbenzofuran (4b) with 2 a yielded only $20 \%$ of the desired product $5 \mathbf{b a}$, which might be due to the electronic effect on the benzofuran. When more KI and higher reaction temperature were employed, the yield of $\mathbf{5 b a}$ was improved to $34 \%$. For substituted 2-phenylbenzofurans, the reaction of $\mathbf{2 a}$ with 5-methyl-2phenylbenzofuran $(\mathbf{4 c})$ gave better yields than the unsubstituted 2-phenylbenzofuran (4b). Notably, 2-methylbenzofuran (4d) could couple with $\mathbf{2 a}, \mathbf{2 e}$ and $\mathbf{2 f}$ smoothly and afforded the thiolation products 5da, 5de and 5df in $60 \%, 44 \%$ and $70 \%$ yield, respectively.

Table 4 Thiolation of 2-substituted benzofurans with aryl sulfonyl chlorides in the presence of $\mathrm{PPh}_{3}{ }^{a}$

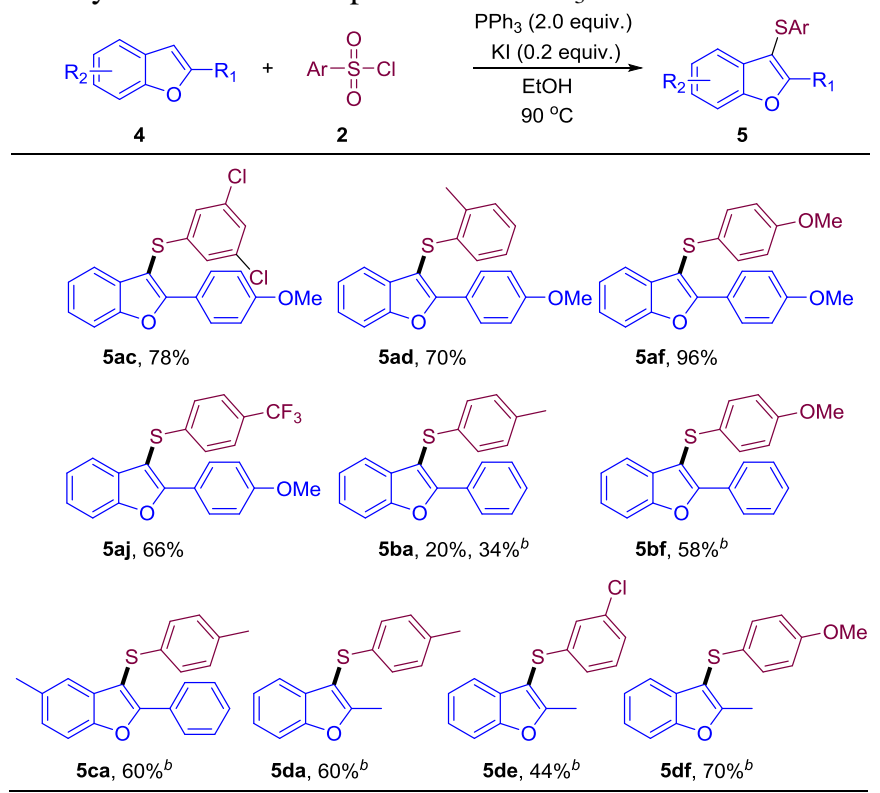

a Reaction conditions: $4 \mathrm{a}-4 \mathrm{~d}(0.5 \mathrm{mmol}), \mathbf{2 a}, \mathbf{2 c}-\mathbf{2 f}(0.6 \mathrm{mmol}), \mathrm{PPh}_{3}(1.0 \mathrm{mmol}), \mathrm{KI}(0.1$ $\mathrm{mmol}), \mathrm{EtOH}(1.0 \mathrm{~mL}), 90{ }^{\circ} \mathrm{C}, 12 \mathrm{~h} .{ }^{b}$ The reaction was carried at $100^{\circ} \mathrm{C}$ and $\mathrm{KI}(0.25$ $\mathrm{mmol}$ ) was used as additive for $24 \mathrm{~h}$.

To further probe the scope of this reaction, 3-substituted benzofurans were examined under the modified optimal reaction conditions. The results are illustrated in Table 5. 3Phenylbenzofuran (6a), 3-(4-methoxyphenyl)benzofuran (6b) and 3-methylbenzofuran (6c) could all be converted to the sulfenylation products smoothly with various aryl sulfonyl chlorides (2a, 2c, $\mathbf{2} \mathbf{f}$ and $\mathbf{2 k}$ ) as sulfenylaiton reagents.

Based on the experiments and previous reports, ${ }^{5}$ a plausible mechanism for these thiolation reactions is proposed (Scheme 2). Initially, aryl sulfonyl chloride $\mathbf{2}$ is reduced by $\mathrm{PPh}_{3}$ via intermediates A-E to sulfenyl chloride $\mathbf{F}$, which is attacked by iodide anion to give sulfenyl iodide $\mathbf{G}$. Electrophilic thiolation of pyrazolone $\mathbf{1}$ as well as benzofuran $\mathbf{4}$ and $\mathbf{6}$ by sulfenylation reagent $\mathbf{G}$ gives the corresponding pyrazolone thioethers, 2-aryl and 3-aryl benzofuran thioethers respectively.
Table 5 Thiolation of 3-substituted benzofurans with aryl sulfonyl chlorides in the presence of $\mathrm{PPh}_{3}{ }^{a}$

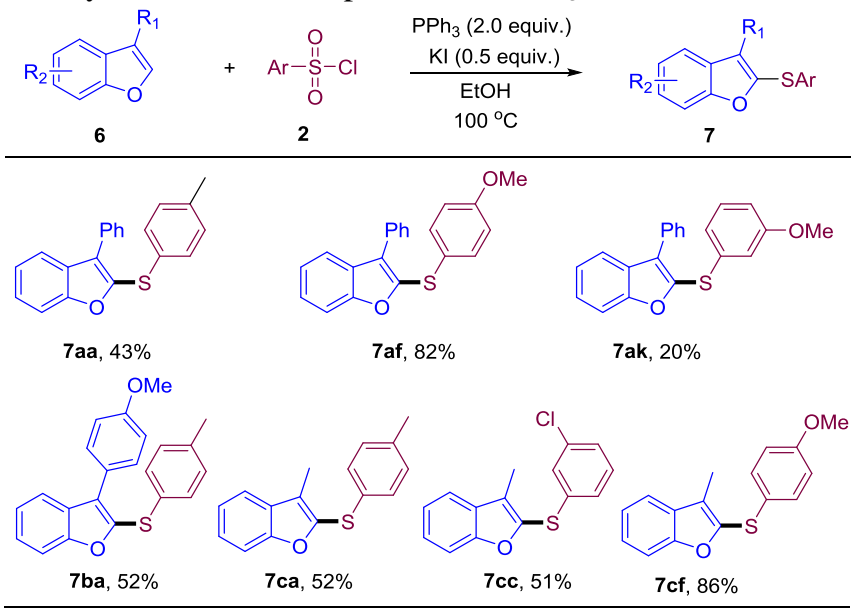

${ }^{a}$ Reaction conditions: $\mathbf{6 a - 6 c}(0.5 \mathrm{mmol}), \mathbf{2 a}, \mathbf{2 c}, \mathbf{2 f}, \mathbf{2 k}(0.6 \mathrm{mmol}), \mathrm{PPh}_{3}(1.0 \mathrm{mmol}), \mathrm{KI}$ $(0.25 \mathrm{mmol}), \mathrm{EtOH}(1.0 \mathrm{~mL}), 100{ }^{\circ} \mathrm{C}, 24 \mathrm{~h}$.
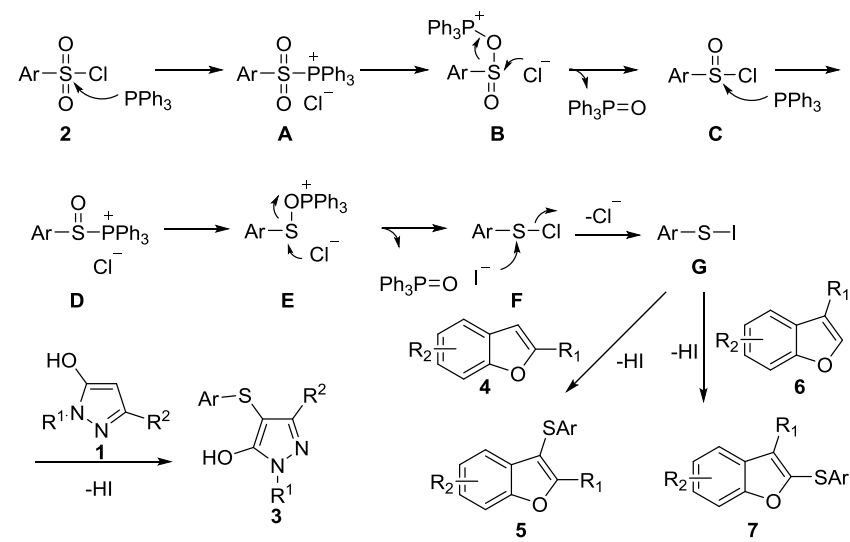

Scheme 2 Proposed reaction mechanism

\section{Conclusion}

In conclusion, we developed a novel and concise method to synthesize pyrazolone thioethers as well as 2-aryl and 3-aryl benzofuran thioethers by using aryl sulfonyl chlorides as sulfenylation reagents. Potassium iodide was demonstrated to facilitate this transformation possibly by generating more reactive sulfenyl iodide in situ from sulfenyl chloride. This study broadened the scope of sulfonyl chloride as novel thiolation reagents in organic synthesis.

\section{Acknowledgments}

The authors sincerely thank the financial support from National Science Foundation of China (Grants 21572158, 21202119, 21202118). The authors also thank Dr. Jing Liu to polish the English of our manuscript.

\section{References and notes}

1. For recent reviews: (a) Shen, C.; Zhang, P.; Sun, Q.; Bai, S.; Hor, T. S. A.; Liu, X. Chem. Soc. Rev. 2015, 44, 291-314. (b) Liu, H.; Jiang, X. Chem. -Asian J. 2013, 8, 2546-2563. (c) Beletskaya, I. P.; Ananikov, V. P. Chem. Rev. 2011, 111, 1596-1636. (d) Kondo, T.; Mitsudo, T. A. Chem. Rev. 2000, 100, 3205-3220.

2. For selected recent examples: (a) Gao, X.; Pan, X.; Gao, J.; Jiang, H.; Yuan, G. Li, Y. Org. Lett. 2015, 17, 1038-1041. (b) Miao, T.; Li, P.; Zhang, Y.; Wang, L. Org. Lett. 2015, 17, 832-835. (c) Johnson, M. W.; Bagley, S. W.; Mankad, N. P.; Bergman, R. G.; Mascitti, V.; Toste, F. D. Angew. Chem. Int. Ed. 2014, 53, 44044407. (d) Zhang, X.; Zeng, W.; Yang, Y.; Huang, H.; Liang, Y. Org. Lett. 2014, 16, 876-879. (e) Reeves, J. T.; Camara, K.; Han, Z. S.; Xu, Y.; Lee, H.; Busacca, C. A.; Senanayake, C. H. Org. Lett. 2014, 16, 1196-1199. (f) Pandya, V. G.; Mhaske, S. B. Org. Lett. 2014, 16, 3836-3839. (g) Xiao, F.; Chen, H.; Xie, H.; Chen, S.; Yang, L.; Deng, G. J.; Org. Lett. 2014, 16, 50-53. (h) Xu, Y.; 
Tang, X.; Hu, W.; Wu, W.; Jiang, H. Green Chem. 2014, 16, 3720-3723.

3. For selected examples: see (a) Uyeda, C.; Tan, Y.; Fu, G. C.; Peters, J. C. J. Am. Chem. Soc. 2013, 135, 9548-9552. (b) Xu, X. B.; Liu, J.; Zhang, J. J.; Wang, Y. W.; Peng, Y. Org. Lett. 2013, 15, 550-553. (c) Kuhn, M.; Falk, F. C.; Paradies, J. Org. Lett. 2011, 13, 4100-4103. (d) Prasad, D. J. C.; Sekar, G. Org. Lett. 2011, 13, 1008-1011. (e) Ke, F.; Qu, Y.; Jiang, Z.; Li, Z.; Wu, D.; Zhou, X. Org. Lett. 2011, 13, 454-457. (f) Park, N.; Park, K.; Jang, M.; Lee, S. J. Org. Chem. 2011, 76, 4371-4378. (g) Fernandez-Rodríguez, M. A.; Hartwig, J. F. Chem.-Eur. J. 2010, 16, 2355-2359. (h) Zhang, S.; Qian, P.; Zhang, M.; Hu, M.; Cheng, J. J. Org. Chem. 2010, 75, 6732-6735.

4. For selected examples: (a) Yang, Y.; Zhang, S.; Tang, L.; Hu, Y.; Zha, Z.; Wang, Z. Green Chem. 2016, 18, 2609-2613. (b) Zhao, X.; Deng, Z.; Wei, A.; Li, B.; Lu, K. Org. Biomol. Chem. 2016, 14, 7304-7312. (c) Rong, G.; Mao, J.; Yan, H.; Zheng, Y.; Zhang, G. J. Org. Chem. 2015, 80, 4697-4703. (d) Zhang, M.; Xie, P.; Zhao, W.; Niu, B.; Wu, W.; Bian, Z.; Pittman, C. U.; Zhou, A. J. Org. Chem. 2015, 80, 4176-4183. (e) Yu, W.; Hu, P.; Fan, Y.; Yu, C.; Yan, X.; Li, X.; Xu, X. Org. Biomol. Chem. 2015, 13, 3308-3313. (f) Hajra, A.; Bagdi, A. K.; Mitra, S.; Ghosh, M. Org. Biomol. Chem. 2015, 13, 3314-3320. (g) Wang, T. T.; Yang, F. L.; Tian, S. K. Adv. Synth. Catal. 2015, 357, 928932. (h) Xu, K.; Khakyzadeh, V.; Bury, T.; Breit, B. J. Am. Chem. Soc. 2014, 136, 16124-16127. (i) Zhang, J.; Shao, Y.; Wang, H.; Luo, Q.; Chen, J.; Xu, D.; Wan, X. Org. Lett. 2014, 16, 33123315. (j) Guo, S.; He, W.; Xiang, J.; Yuan, Y. Chem. Commun. 2014, 50, 8578-8581. (k) Yang, F. L.; Wang, F. X.; Wang, T. T.; Wang, Y. J.; Tian, S. K. Chem. Commun. 2014, 50, 2111-2113. (l) Kang, X.; Yan, R.; Yu, G.; Pang, X.; Liu, X.; Li, X.; Xiang, L.; Huang, G. J. Org. Chem. 2014, 79, 10605-10610. (m) Yang, F. L.; Tian, S. K. Angew. Chem. Int. Ed. 2013, 52, 4929-4932. (n) Singh, R., Raghuvanshi, D. S.; Singh, K. N. Org. Lett. 2013, 15, 4202-4205. (o) Singh, N.; Singh, R.; Raghuvanshi, D. S.; Singh, K. N. Org. Lett. 2013, 15, 5874-5877. (p) Li, X.; Xu, X.; Hu, P.; Xiao, X.; Zhou, C. J. Org. Chem. 2013, 78, 7343-7348.

5. Wu, Q.; Zhao, D.; Qin, X.; Lan, J.; You, J. Chem. Commun. 2011, 47, 9188-9190.

6. Chen, M.; Huang, Z. T.; Zheng, Q. Y. Chem. Commun. 2012, 48, $11686-11688$.

7. Zhao, X.; Zhang, L.; Li, T.; Liu, G.; Wang, H.; Lu, K. Chem. Commun. 2014, 50, 13121-13123.

8. Zhao, X.; Zhang, L.; Lu, X.; Li, T.; Lu, K. J. Org. Chem. 2015, 80, 2918-2924.

9. Zhao, X.; Li, T.; Zhang, L.; Lu, K. Org. Biomol. Chem. 2016, 14, $1131-1137$.

10. General procedure of thiolation of pyrazolones with aryl sulfonyl chloride in the presence of $\mathrm{PPh}_{3}$ : Pyrazolones 5-methyl-2-phenyl2,4-dihydro-3H-pyrazol-3-one (1a) $(87 \mathrm{mg}, \quad 0.5 \mathrm{mmol}), 4-$ methylbenzenesulfonyl chloride (2a) $(114 \mathrm{mg}, 0.6 \mathrm{mmol}), \mathrm{PPh}_{3}$ (262 mg, $1.0 \mathrm{mmol})$ and $\mathrm{KI}(17 \mathrm{mg}, 0.1 \mathrm{mmol})$ in 1,4-dioxane (1.0 $\mathrm{mL}$ ) were mixed in a sealed tube. The mixture was stirred at $80^{\circ} \mathrm{C}$ for 12 hours. Then, the solvent was evaporated under reduced pressure and the residue was purified by silica gel column chromatography to afford 3-methyl-1-phenyl-4-(p-tolylthio)- $1 \mathrm{H}$ pyrazol-5-ol (3aa) (133 mg, 90\%) as a white solid. 


\section{Graphical Abstract}

Potassium Iodide Promoted Thiolation of

Pyrazolones and Benzofurans Using Aryl Sulfonyl Chlorides as Sulfenylation Reagents

Xia Zhao,* Xiaoyu Lu, Aoqi Wei, Xiaoliang Jia, Jun Chen and Kui Lu*
Leave this area blank for abstract info.

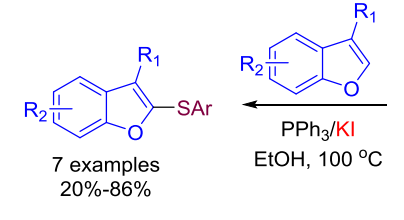

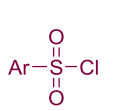

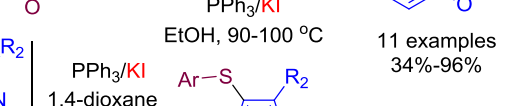

